\title{
Individual tree detection and characterization using 3D remote sensing
}

\author{
Mikko Vastaranta ${ }^{1}$, Ninni Saarinen ${ }^{1,2}$, Tuomas Yrttimaa ${ }^{1}$, Ville Kankare ${ }^{1}$ \\ ${ }^{1}$ School of Forest Sciences, University of Eastern Finland, Joensuu, 80101, Finland \\ ${ }^{2}$ Department of Forest Sciences, University of Helsinki, Helsinki, 00014, Finland; \\ mikko.vastaranta@uef.fi, ninni.saarinen@helsinki.fi, tuomas.yrttimaa@uef.fi, \\ ville.kankare@uef.fi
}

\begin{abstract}
Here, we will cover individual tree detection and characterization using 3D remote sensing. Simply, it means that point clouds are collected over a forested area using airborne laser scanning (ALS) or created using photogrammetric image interpretation and further used to detect individual trees using different algorithms. After the tree detection, the attributes of interest are predicted for each tree. We try to consistently use the terms "individual tree detection and characterization" or "individual tree detection" and "individual tree characterization" separately referring to different methodological steps. In the scientific remote sensing literature, terms individual tree detection (ITD), individual tree crown approach (ITC) and single tree inventory $(\mathrm{STI})$ are also often used and most often they refer to the same thing. We'll start by discussing why we need information from single trees. Then we go through the methodological steps that are used in individual tree detection and characterization: 1) remote sensing and field data collection, 2) data types and processing, 3) tree detection algorithms, and 4) methods for prediction of tree attributes. The current methodological state-of-the-art in individual tree detection and characterization is described before we'll finally present some example applications in biodiversity monitoring, urban forestry and wood procurement planning.
\end{abstract}

\section{Why do we need information from single trees?}

When looking at this kind of forested landscape (Figure 1), we easily start to think that do we really need single tree information over vast areas? Is information from single trees really needed for science, forest management planning, carbon assessments and so on? Would it be enough to have forest inventory attribute rasters or information only for forest stands? Forests in Finland are covering only $0.5 \%$ of all the forests in the world and already here in Finland, it would be challenging to handle information from each tree at the national scale. 


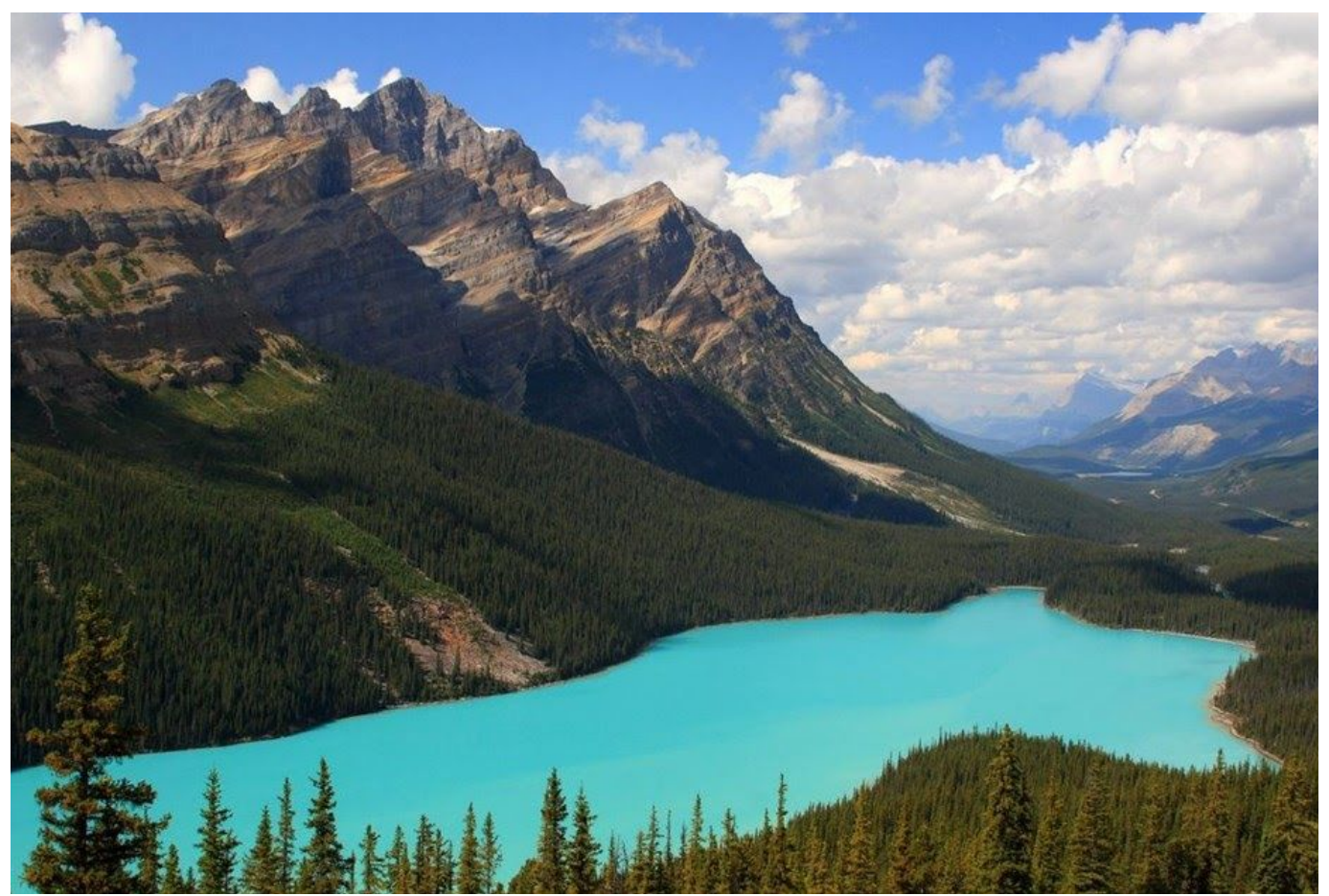

Figure 1. Single forest landscape can already include millions of trees.

Information from single trees is definitely required for many scientific purposes. Information on single trees is required to understand the phenomena and processes that are happening in our forests (Vastaranta et al., 2020). There is no phenomenon that is happening only at the scale of a stand or raster cell. Forest growth is a sum of tree growth processes, and forest dynamics is all about interactions between single trees. Similarly, forest attributes are composed of individual tree attributes. For example, growing stock volume is the sum of the stem volumes of single trees. In forest management and wood procurement planning, single tree information is not necessarily required, but it could be highly beneficial, because we are often interested in single tree attributes or from attributes that are directly linked to single tree attributes, such stem number, basal area, mean volume, diameter and height (Figure 2). 


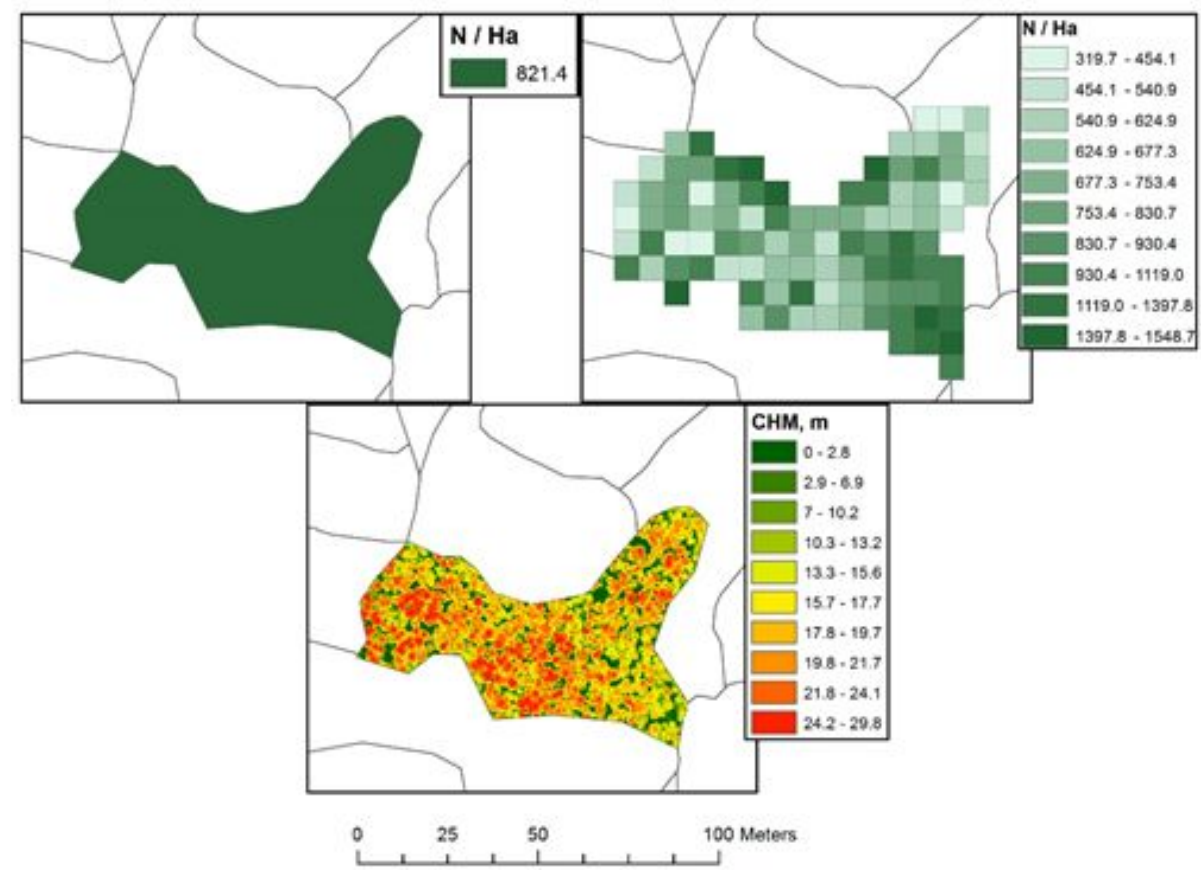

Figure 2. Single tree information could be beneficial for forest management and wood procurement planning. We should move from stand and raster level information (left) towards detailed characterization of single trees (See Figure 6). (C) Ville Kankare

Private forest owners and the forest industry may also have different kinds of information needs. If we think about economic aspects, they are affected by tree quality, amount of timber assortments, forest growth and scheduling of the operations. Decision making regarding all of these could benefit from tree-level information. Even now, forest management planning calculations are computed using single tree information, but calculations are using simulated not truly measured trees. Single tree information could be beneficial for continuous cover forestry as it requires information from tree size distributions. Tree map could be obtained from single tree inventories and it could provide many additional benefits for forest management and wood procurement planning, such as improved harvesting planning and growth update as spatial distribution of the trees would be known. In addition, some things are problematic for the area-based approach (ABA) that is currently used for providing raster- and stand-level forest information (Holopainen et al., 2014; White et al., 2013). For example, accuracy of the species-specific forest inventory attributes is rather limited and that leads to inaccurate predictions for tree size distributions (Siipilehto et al., 2016). Currently there aren't any theories or research ideas presented that could provide major improvements to ABA. Although, it should be noted that individual tree detection-based forest inventories have problems as well. We'll cover those problems later when describing the state-of-the-art. There are also trees that need to be monitored, but are not growing in a forest environment. For example, individual tree detection and characterization methods are needed for providing information for urban forestry and management of street trees in cities (Figure 3). 


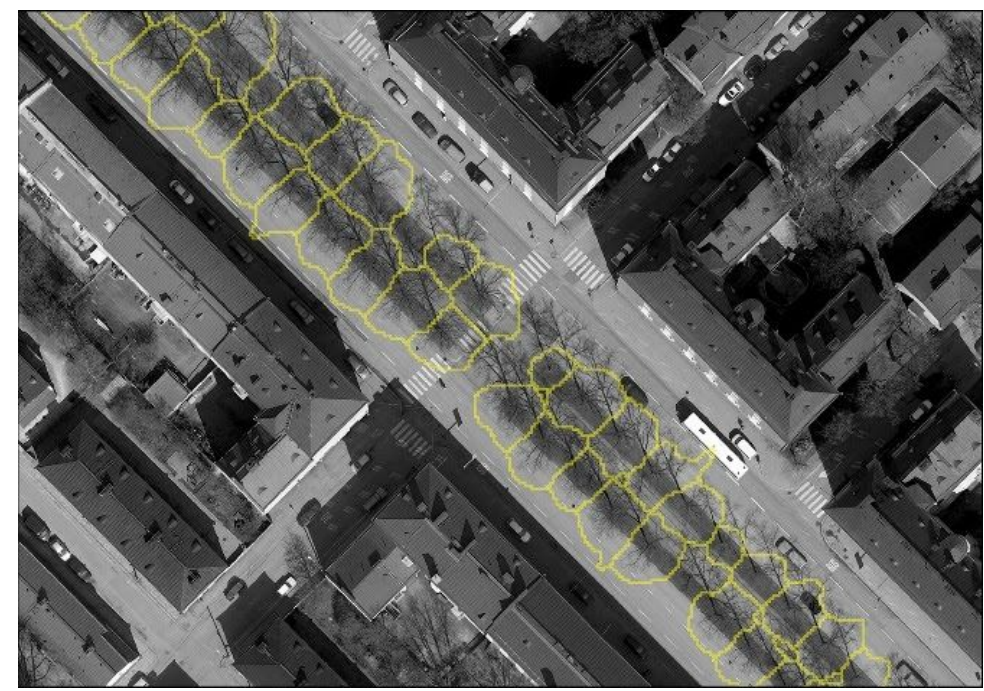

Figure 3. City of Helsinki is updating its tree register using remote sensing-based individual tree detection and characterization techniques. @Topi Tanhuanpää

To summarize, natural processes and phenomena are not happening at the raster cell level. To understand these processes, such as forest growth, single tree information is needed or at least it would be highly beneficial to use it. For sure, there are applications or information needs that require information from trees and then there are applications where more generalized information (e.g. raster- or stand-level forest attributes) is suitable. Thus, it is important to make informed decisions when selecting the most suitable forest mapping techniques or data sources for some specific use-case. If single tree information is not used, we are simplifying many things. However, it should be noted that sometimes it makes sense to simplify things. If we think about science, carbon assessments, biodiversity, habitat assessments and forestry, most probably all of these would benefit from single tree information, but certainly, it is not absolutely necessary. According to our current understanding, if we want to push things forward, then we are pushing things towards more comprehensive use of single tree information in forest sciences and forestry.

\section{Single tree inventory techniques}

\section{Data acquisition and processing}

According to literature review by Zhen et al. (2016) active remote sensing, mainly ALS data, has been the most used remote sensing data set for single tree detection (Figure 4). However, nowadays use of photogrammetric point clouds have rapidly increased and these percentages might have changed a bit. White et al., (2013) provides a good review of the utility of the image-based photogrammetric point clouds as well as comparisons to ALS. 


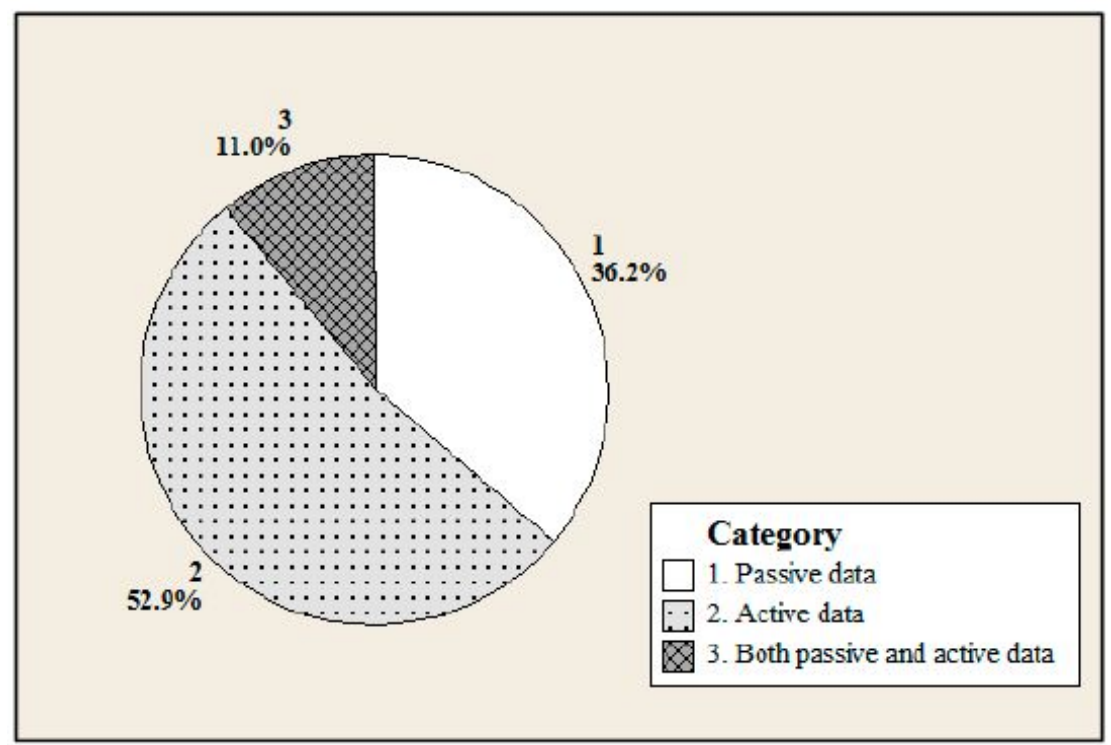

Figure 4. Summary of remotely sensed data used in individual tree detection (Zhen et al., 2016).

Here, we are not going into details of measurement principles of ALS. If you are not familiar with those, please see Hyyppä et al. (2018) or Holopainen et al. (2013, in Finnish). As the most of the tree detection methods are based on point clouds, it is important to be aware of the differences between ALS and image-based point clouds. There are also radargrammetric and interferometric point clouds, but point density in those isn't usually suitable (dense enough) for single tree detection (Magnard et al., 2016; Vastaranta et al. 2018). It has been stated that individual tree detection would need at least 2 pulses per $\mathrm{m}^{2}$ (Kaartinen et al., 2012). This was an issue 10-years ago, but nowadays, most of the new ALS datasets are denser than that. Next countrywide ALS coverage from Finland will be more than 5 pulses per $\mathrm{m}^{2}$. Photogrammetric point clouds can be created using satellite imagery (Vastaranta et al., 2018), aerial imagery (Vastaranta et al., 2013), drone-collected imagery (Saarinen et al., 2018) or images collected under the canopy (Liang et al., 2014). The main difference between ALS and photogrammetric point clouds is that laser pulses can penetrate through the canopy, but the photogrammetric point clouds mainly describe the outer canopy envelope (See Figure 5). Theoretically most of the methods can describe the outer canopy surface with similar detail. If your tree detection method is only using information about the outer canopy surface, both kinds of point clouds should work. Then differences in the laser pulse density or imaging geometry are the most important things that affect tree detection. It should be noted that photogrammetric point clouds are typically much denser than ALS point clouds, but the additional point density have not led to better tree detection accuracies (Hirschmugl et al., 2007). In addition to remote sensing data, some amount of field-measured trees are usually needed for single tree characterization depending what kind of attributes you would like to predict for each tree. We will cover this topic a bit later, but the general rule is that you should measure all the attributes in the field that you would like to predict later. 
DSI

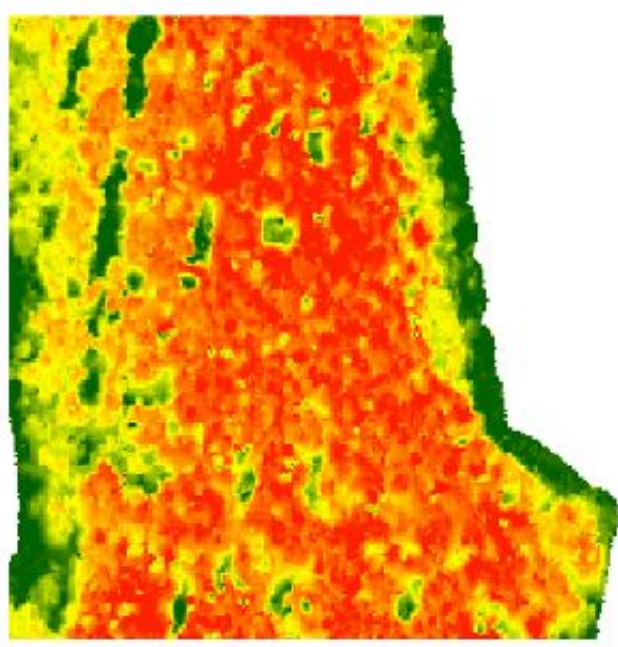

ALS

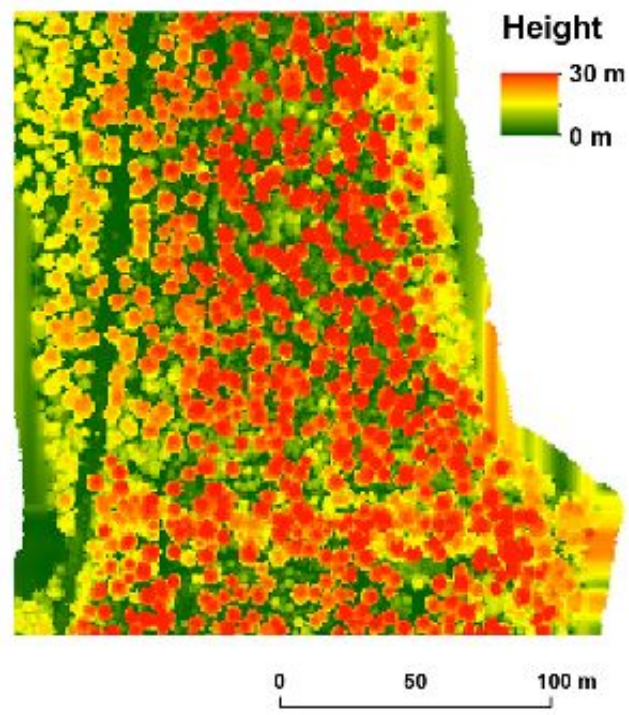

Figure 5. Laser pulses can penetrate the canopy, but the photogrammetric point clouds mainly describe the outer canopy envelope. Small canopy gaps are also better characterized in ALS-based CHM than by photogrammetry-based CHM (DSI).

The most common data types that are used for single tree detection and characterization are point cloud, raster and voxel. A point cloud is a set of data points in space. There can be multiple attributes for each point in 3D-space including return intensity, GPS time and return type. Probably the most common data type that is used for tree detection is raster and more specifically canopy height model $(\mathrm{CHM})$ in a raster format (Figure 5). Raster resolutions varying from $0.2 \mathrm{~m}$ to $2 \mathrm{~m}$ are typically used. In boreal forest conditions resolution of 0.5 has produced good results in general (e.g. Yu et al., 2011). Then there are tree detection methods that are based on voxels. A voxel represents a value on a regular grid in three-dimensional space (Figure 6). Voxel representation makes analyses of 3D information straight forward. Voxels simplify point cloud-based representation of trees, but provide a more comprehensive description of the trees than is possible with rasters due to their third dimension. 
A

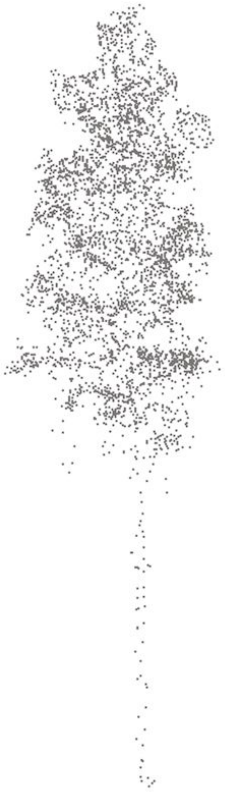

B

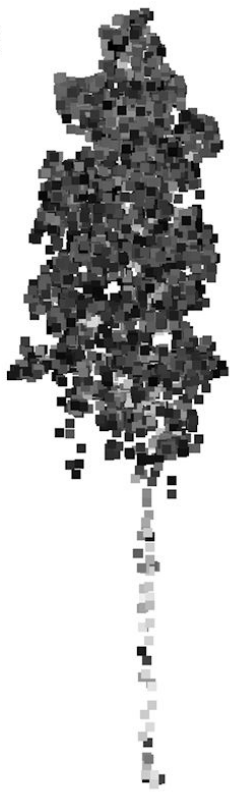

C

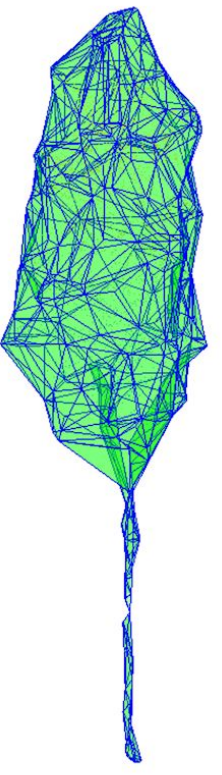

D

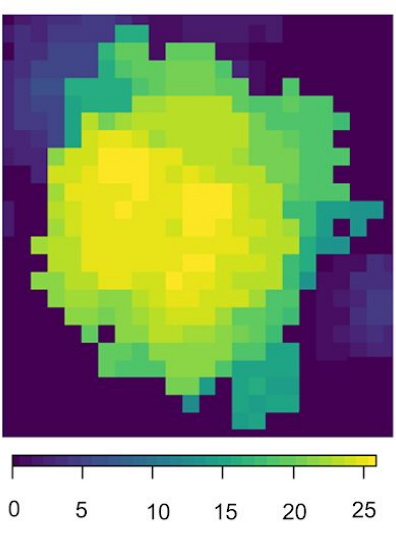

Figure 6. A point cloud (A), voxelization (B), alpha-shapes and canopy height model (raster) describing a single tree.

\section{Single tree detection methods and algorithms}

Next we'll outline some example tree detection methods based on rasters, voxels and point clouds as well as some modifications of these (Figure 6). It can be seen from Figure 7 that most of the tree detection methods are based on rasters.

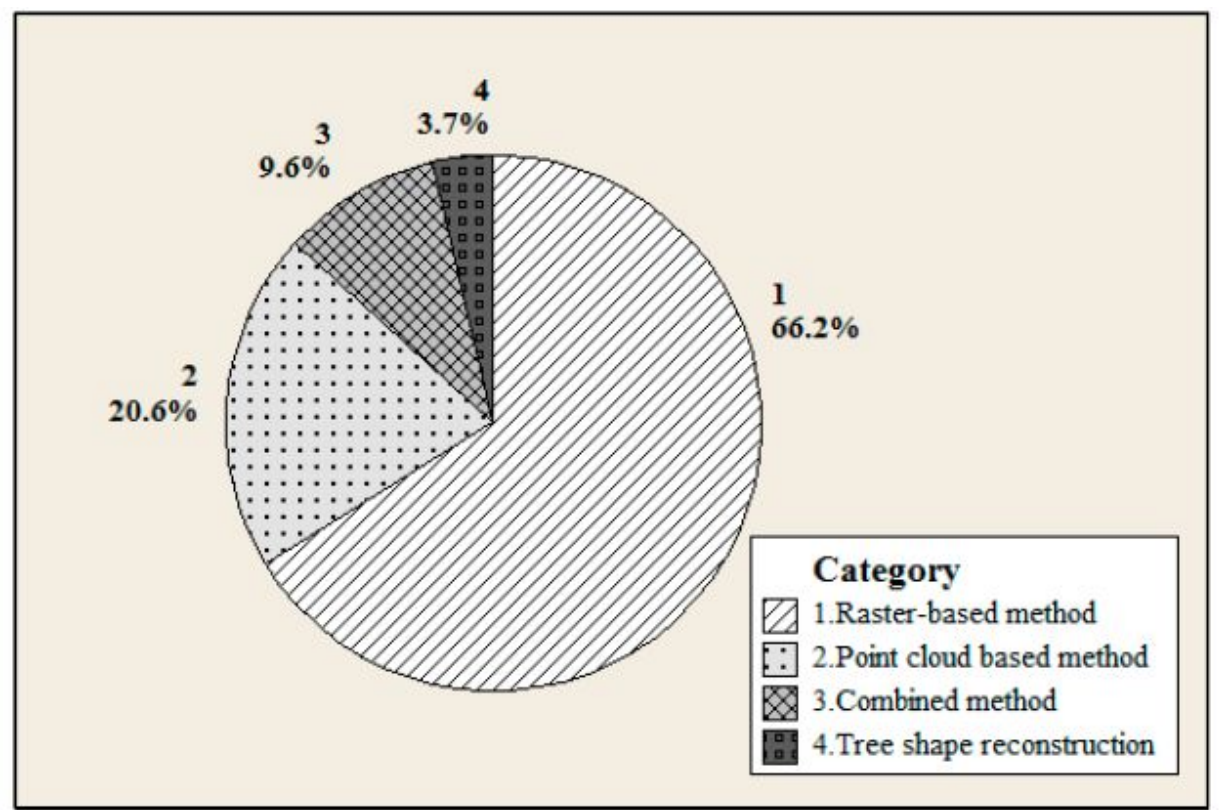

Figure 7. Summary of tree detection methods (Zhen et al., 2016). 
In this raster-based single tree detection and crown segmentation, Zawawi et al. (2015) used ALS-data with 5 pulses per $\mathrm{m}^{2}$ (Figure 8). They created a digital terrain model (DTM), digital surface model (DSM) and CHM with a resolution of $0.5 \mathrm{~m}$ by subtracting DTM from DSM. Then they smoothed $\mathrm{CHM}$ to eliminate spurious local maxima caused by tree branches etc. How much smoothing is required varies a lot between forest types and is also dependent on the used resolution of the $\mathrm{CHM}$. Then local maxima detection was applied. It can be based on fixed or varying-sized moving windows depending on the forest structure (Eysn et al., 2015). Crown segmentation was then based on watershed segmentation (Figure 9). It should be noted that tree crowns can also be segmented without local maxima detection. In some single tree detection techniques, a priori information is used to set a stand-specific smoothing parameters or local maxima window size (Koch et al., 2006).

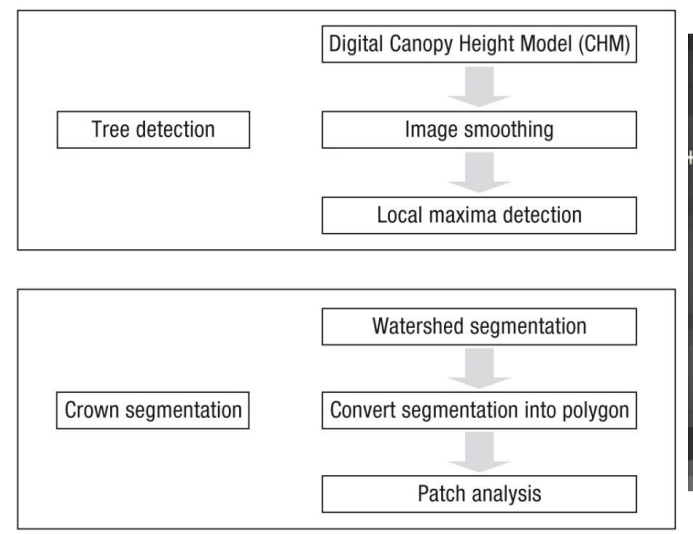

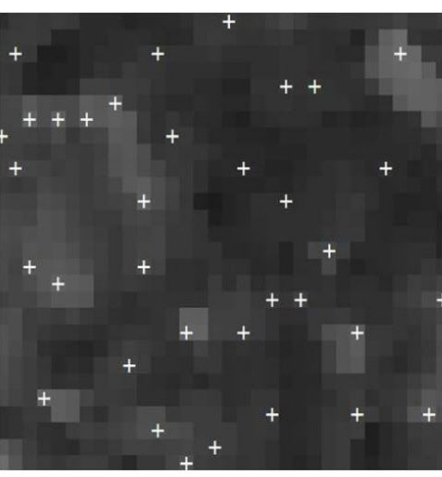

(a)

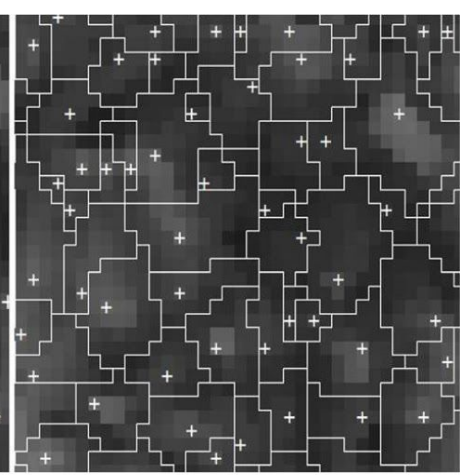

(b)

Figure 8. Left: example workflow for tree detection and crown segmentation with rasters (Zawawi et al., 2015). (a) Grayscale image of the filtered canopy height model (CHM) marked by local maxima seeds identified as tree tops (b) Segmented image interpreted as tree crowns derived from the watershed segmentation method. 


\begin{tabular}{|l|l|l|l|l|l|}
\hline 14 & 18 & 23 & 24 & 22 & 21 \\
\hline 16 & 20 & 25 & 26 & 24 & 19 \\
\hline 18 & 22 & 24 & 25 & 23 & 18 \\
\hline 24 & 23 & 23 & 24 & 17 & 15 \\
\hline 25 & 27 & 26 & 21 & 16 & 3 \\
\hline 25 & 21 & 22 & 18 & 15 & 2 \\
\hline
\end{tabular}

\begin{tabular}{|c|c|c|c|c|c|}
\hline 2 & 2 & 2 & 4 & 8 & 8 \\
\hline 2 & 1 & 1 & & 16 & 16 \\
\hline 4 & 128 & 128 & 64 & 16 & 32 \\
\hline 2 & 4 & 8 & 8 & 32 & 32 \\
\hline 1 & & 16 & 16 & 32 & 32 \\
\hline 128 & 64 & 32 & 32 & 32 & 32 \\
\hline
\end{tabular}

C
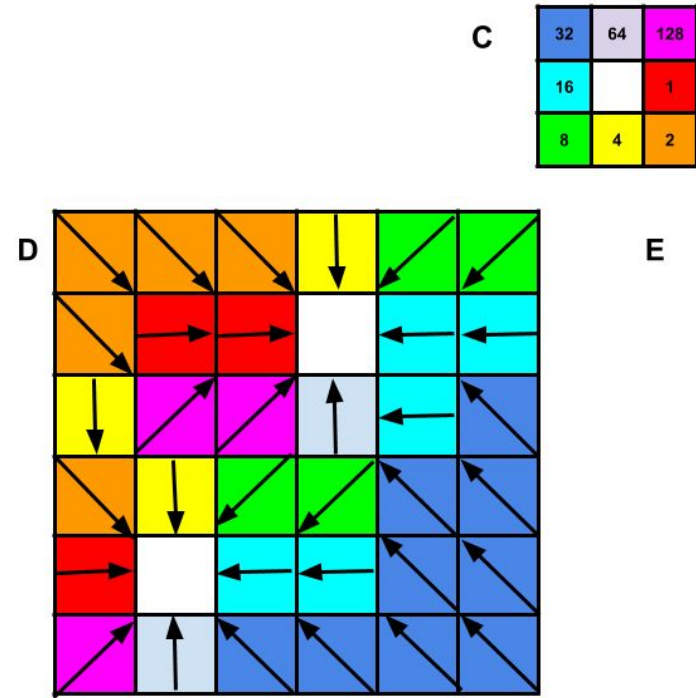

E

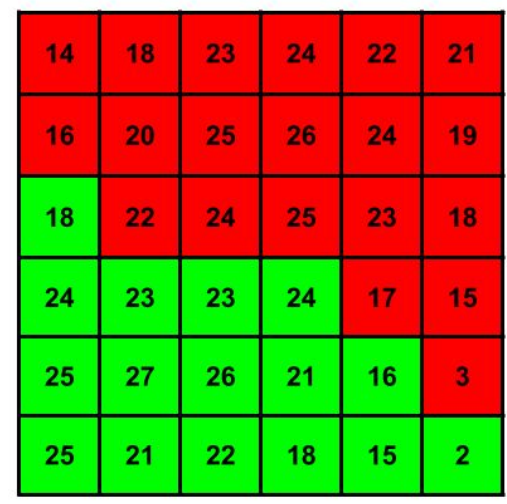

Figure 9. Tree crown segmentation can be done using watershed segmentation. A: Elevation surface, such as canopy height model. Raster cell values are meters above the ground level. B: Reversed flow direction is calculated and coded as presented in C. Then, reversed flow directions (D) can be used to create segments $(\mathrm{E})$.

In watershed segmentation, $\mathrm{CHM}$ is used as an elevation surface (Figure 9) and flow direction is derived for each cell and used to create watersheds, in other words crown boundaries in the case of tree detection. Wang et al. (2008) developed a tree detection approach in which they inspected horizontal distribution of canopy layers (Figure 10). First, different canopy layers were voxelized and then 2D horizontal projections of normalized points of different canopy layers were created. Then morphological operations were used to create canopy layers for varying heights. Finally, the tree detection was based on examination of overlapping areas between two canopy layers. With this kind of approach, it was also possible to detect non-dominant trees. 


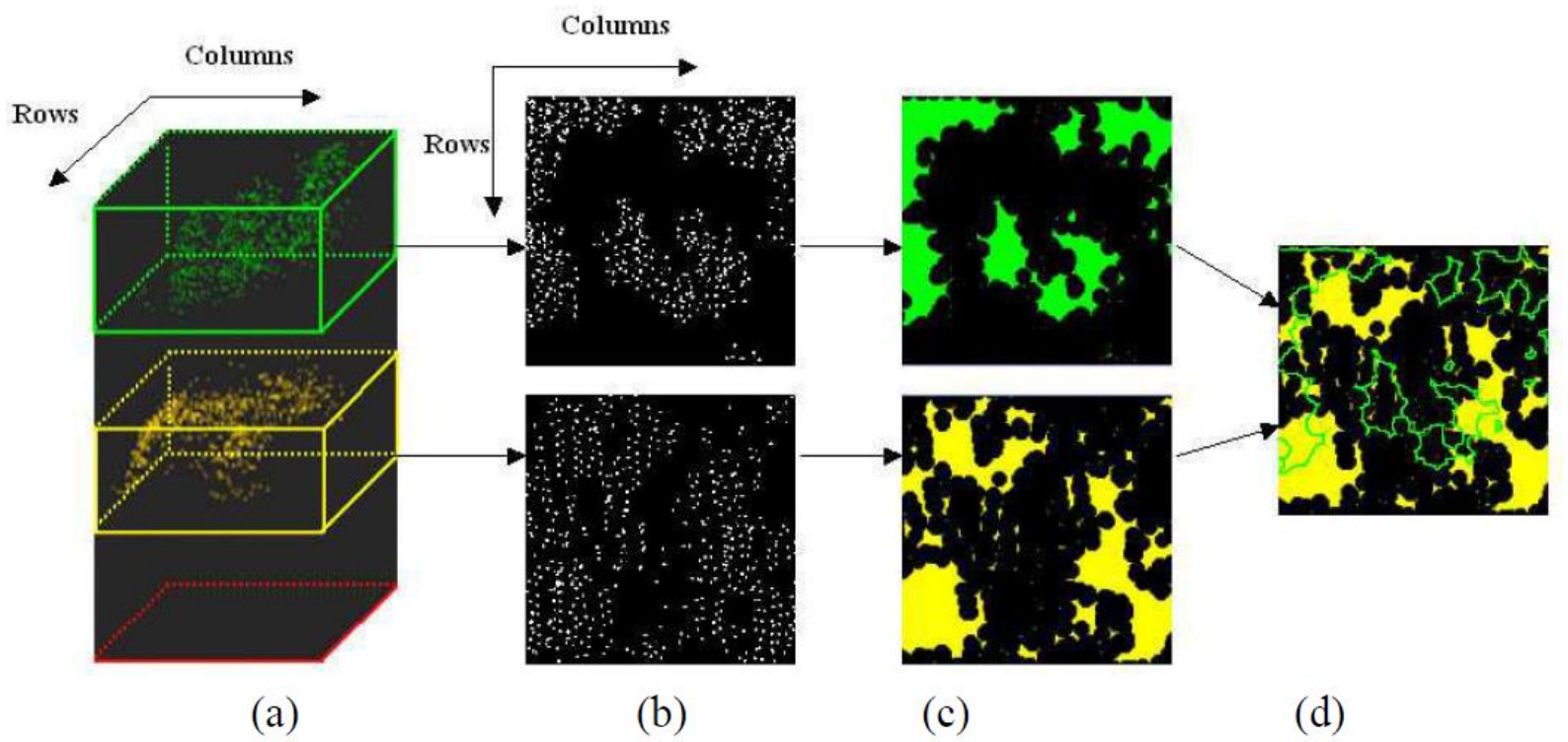

Figure 10. Voxel and point cloud-based approaches are capable of detecting suppressed trees. Workflow presented by Wang et al. (2008). a) 3D spatial distribution of normalized points of different canopy layers; b) 2D horizontal projections of normalized points of different canopy layers; c) horizontal distributions of different canopy layers; d) examination of overlapping area between two canopy layers.

There are some advanced raster-based techniques that, at least theoretically, can be used to detect both the dominant and suppressed trees (Hyyppä et al., 2012). In that study, several raster-layers from points of different return type (i.e. first, only, last) were created and typical tree detection and segmentation methods (i.e. local maxima detection and watershed segmentation) applied for those layers. In some cases, trees were detected better from those alternative raster layers instead of CHM (Figure 11).

\section{Prediction of tree characteristics}

After the trees have been detected and crowns segmented in the area of interest, tree attributes and characteristics are usually predicted. Before you start to collect ALS data and field data, you should be thinking about what attributes can be predicted with remote sensing-based single tree characterization techniques and with sufficient accuracy for your information needs. After the tree detection, $\mathrm{XYZ}$ position of tree tops is already available as well as crown boundaries. So, the common premise is that tree top position is the same as tree base position. Of course there may be small differences between these two positions, but for most of the applications, tree top position can be used as a proxy for tree position without any issues. If local maxima has not been detected, it is relatively straightforward to derive tree position based on the highest point return within a crown segment. Although tree detection would have been based on rasters or voxels, point cloud information is often used in addition to raster and voxel information in the tree characterization step. Usually, point clouds within a crown segment are clipped and used to 
characterize a tree and for calculation of metrics describing the tree (Figure 12). In forest sciences or in forestry, typical attributes of interest include tree species, tree height, diameter at breast height (dbh), stem volume, biomass and various crown parameters, such as diameter, length and volume. Thus, the important question is what kind of dependencies and linkages there is between the point cloud and the attributes of interest. Look at Figure 5 and think what kind of tree attributes are easy to predict and what are more challenging.
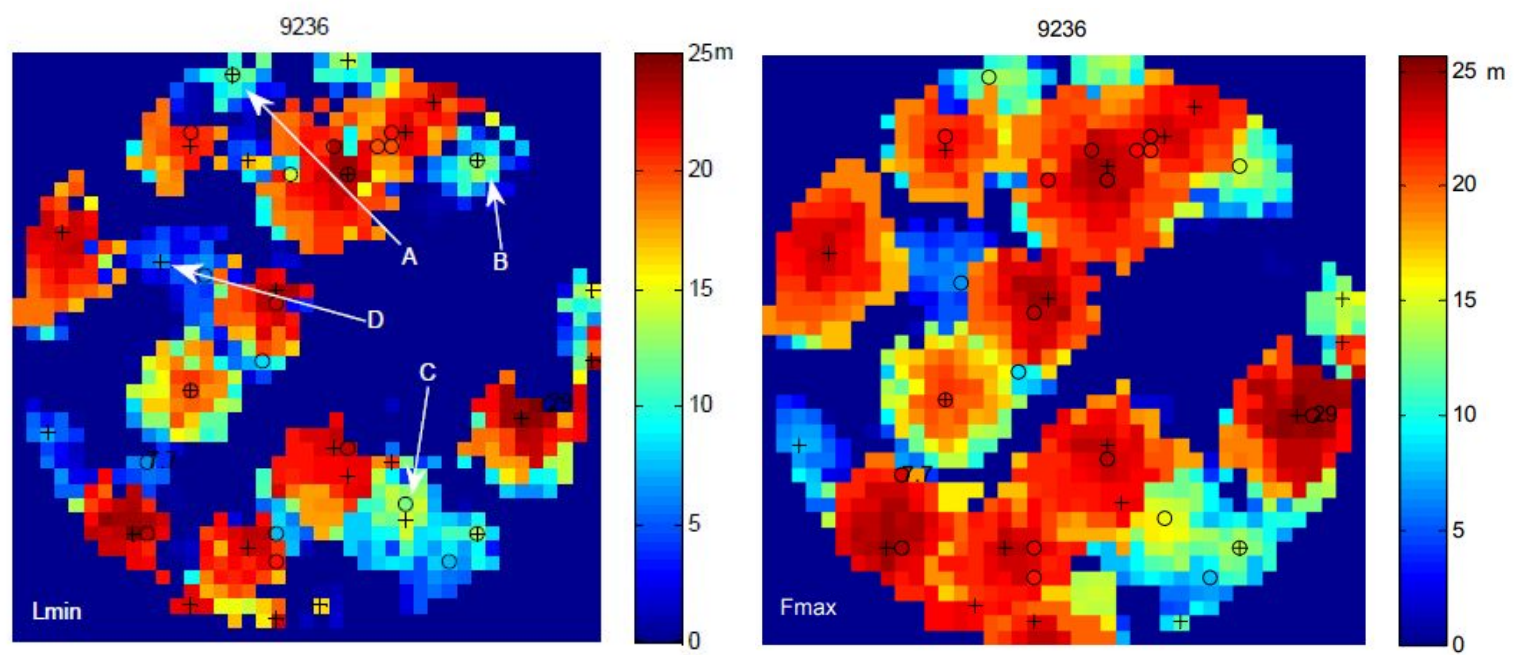

Figure 11. Two raster layers, Lmin ("surface model" created from minimum values of last returns) (left) and Fmax (typical canopy height model) (right). Detected trees are marked as "+" and field-measured trees as "O". The trees A, B, C and D were detectable from the Lmin layer, but not from CHM (Fmax). (Hyyppä et al. 2012)

For single tree characterization, some amount of modelling data is typically required (Figure 12) as field-measured trees are used for developing prediction models. It is important that field-measured trees can reliably be linked with the crown segments. Thus, a global navigation satellite system capable of recording high positional accuracy should be used in the field. Predictors often used in the regression models or inputs into machine learning include height-related metrics ( $\mathrm{Yu}$ et al., 2011). These metrics are similar to metrics that are used in ABA, but are calculated using the points within one crown segment (i.e maximum height, mean height, height percentiles, density of the crown, etc.). Crown area and dimensions can be used as predictors, as well as crown shape and volume. Convex hull and alpha shapes are common techniques used to characterize tree crowns (Vauhkonen et al., 2010, Figure 6). If an ALS point cloud is used and intensity of the returns is recorded, in theory, intensity features can be used to describe scattering characteristics of the tree crown. However, it should be noted that ALS intensity values recorded by most of the systems may be uncalibrated and thus practically useless without calibration. With photogrammetric point clouds, spectral information can be used in addition to 3D metrics in the prediction of tree-level attributes of interest. 


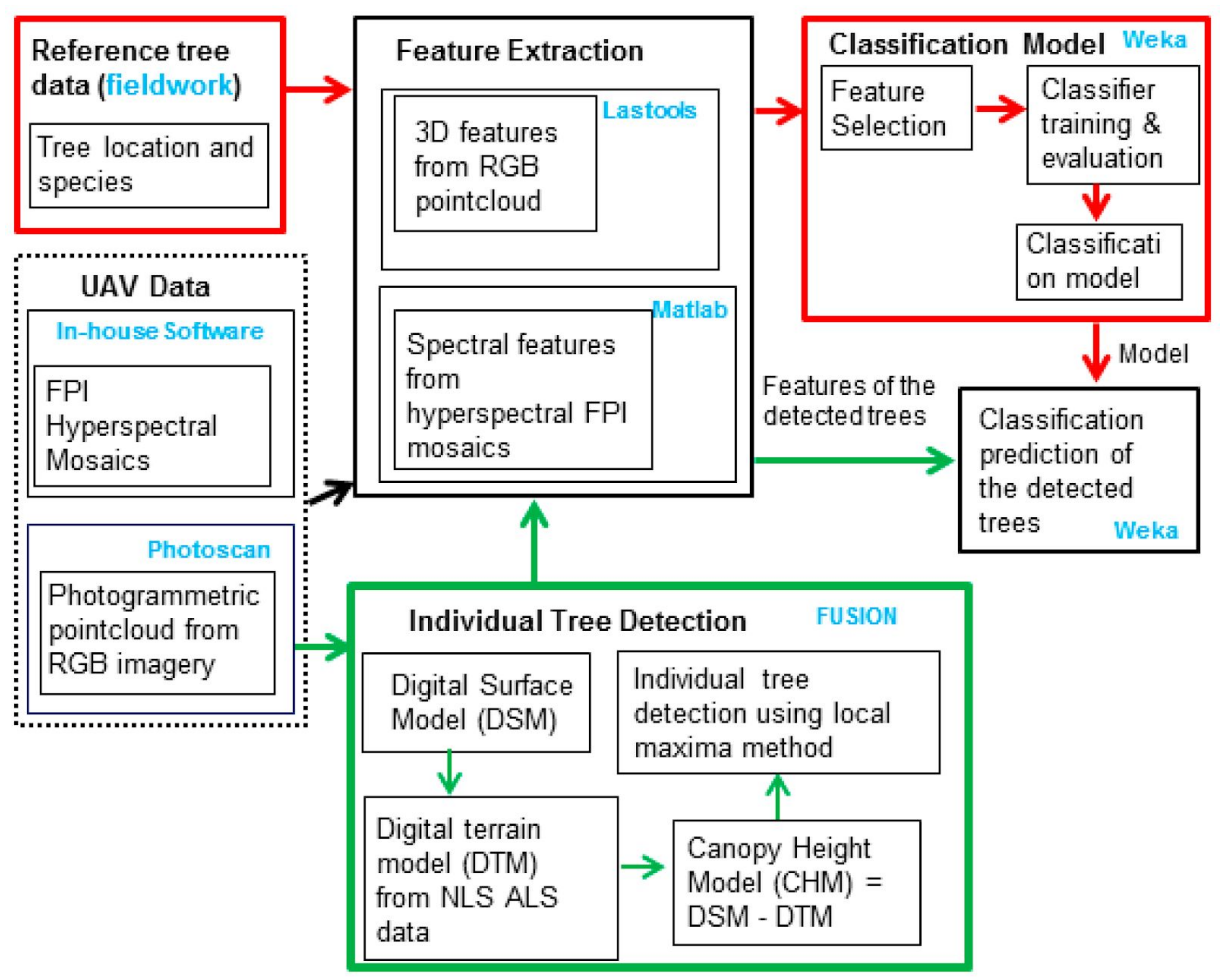

Figure 12. Workflow to obtain tree attributes using field data, hyperspectral imagery and photogrammetric point cloud (Nevalainen et al. 2017).

\section{Current methodological state-of-the-art in single tree detection}

There have been international benchmarking studies where feasibility of the current single tree detection methods have been evaluated. The objective of the "Tree Extraction" project organized by EuroSDR (European Spatial data Research) and ISPRS (International Society of Photogrammetry and Remote Sensing) was to evaluate the quality, accuracy, and feasibility of automatic tree detection methods, mainly based on ALS data (Kaartinen et al., 2012). It included several partners around the world and the study areas located in Espoo, Finland. Tacheometer and terrestrial laser scanning measurements were used as a reference. For more details, including detailed descriptions of the evaluated algorithms, see open access article by Kaartinen et al. (2012). Based on the study, there is a large range in tree detection accuracy varying from $30 \%$ to $100 \%$ (Figure 13). In general, dominant trees can be detected rather accurately (>90\% from the trees, close to $100 \%$ from the stem volume). For all of the methods, detection of the clustered trees was more challenging. For clustered trees, tree detection accuracies close to $70 \%$ were obtained with the best performing tree detection algorithms. Suppressed trees were detected poorly. The best performing algorithms were capable of detecting $40 \%$ of the suppressed trees, but most of the algorithms detected only approximately $20 \%$ of the suppressed trees. With almost all of the methods, the tree height is determined without bias and with RMSE less than $1 \mathrm{~m}$. The position of the tree is determined with RMSE less than $1 \mathrm{~m}$, respectively. 


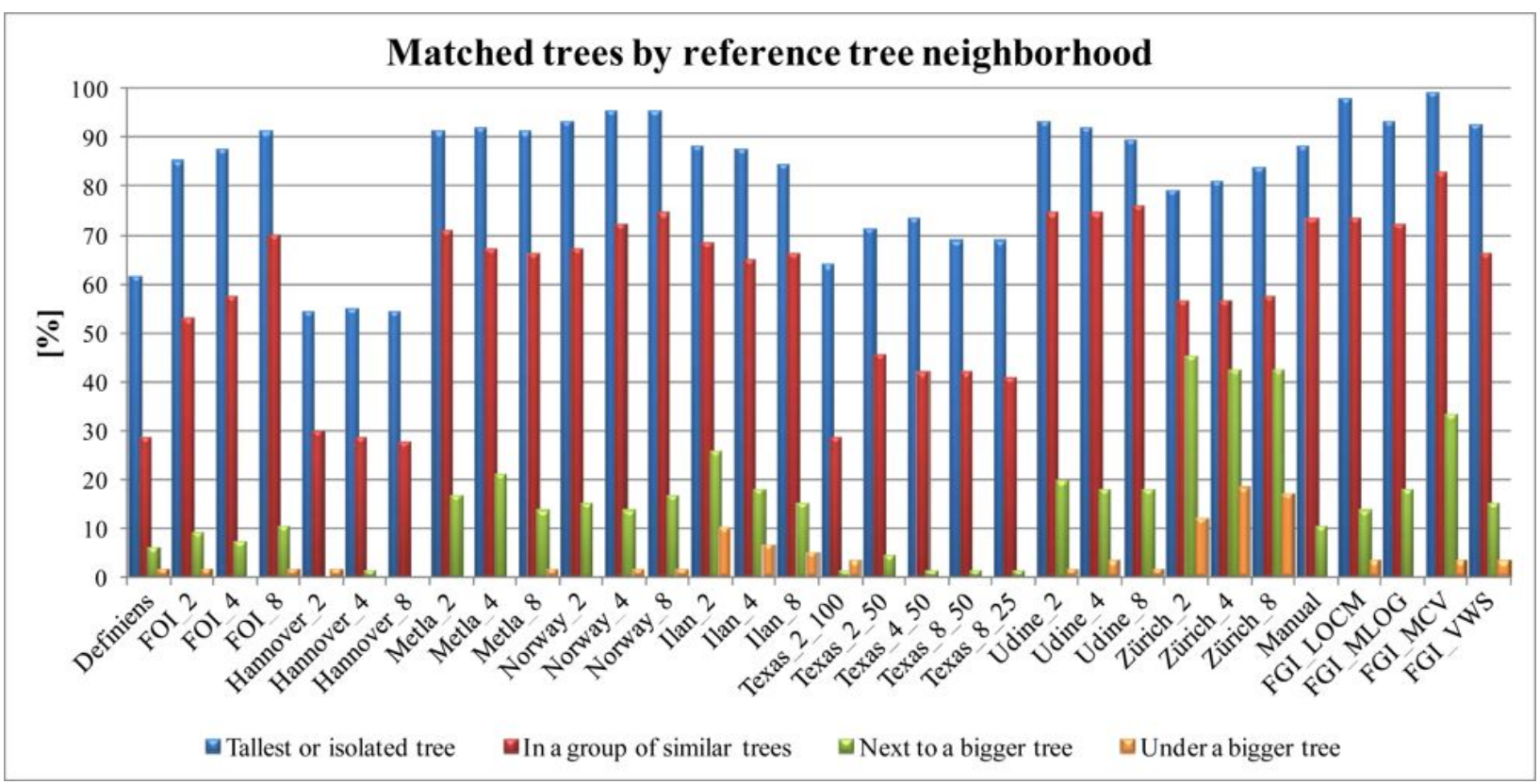

Figure 13. Dominant trees can be detected rather accurately from airborne laser scanning data. (Kaartinen et al. 2012)

Vauhkonen et al. (2012) did a comparative testing of single-tree detection algorithms under different types of forests. In their study, ALS data and corresponding field data were acquired from boreal forests in Norway and Sweden, coniferous and broadleaved forests in Germany, and tropical pulpwood plantations in Brazil. Treetop positions were extracted using six different algorithms developed in Finland, Germany, Norway, and Sweden. Then the accuracy of tree detection and height estimation was assessed. According to Vauhkonen et al. (2012) forest structure strongly affected the performance of all algorithms. The success of tree detection was found to be dependent on tree density and clustering. The differences in performance between methods were more pronounced for tree detection than for height estimation. The algorithms showed a slightly better performance in the conditions for which they were developed, while some could be adapted by different parameterization according to training with local data.

\section{Example applications for single tree detection and characterization}

Forest biodiversity can be assessed based on single tree detection and characterization techniques (Figure 14). Saarinen et al. (2018) detected single trees from photogrammetric CHM using watershed segmentation. The photogrammetric point cloud was created using drone-captured Red Green Blue (RGB)-imagery and image matching. With field-measured trees a random forest regression model was trained and it predicted species, dbh, height and health status for each tree. The best predictors were height metrics and spectral features derived from hyperspectral imagery that was captured simultaneously with RGB-imagery. From the predicted tree attributes following biodiversity indicators were calculated: species richness, amount of dead wood, structural heterogeneity, successional stage, and amount of large deciduous trees. 


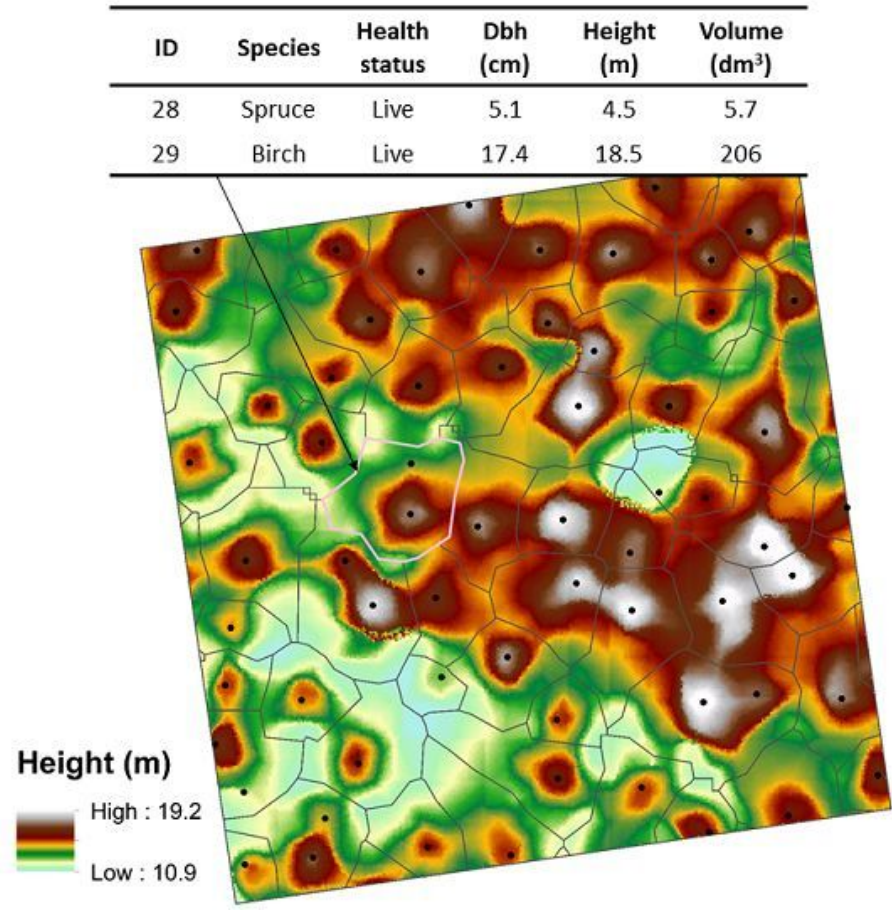

Figure 14. Forests biodiversity indicators can be assessed based on single tree detection and characterization techniques (Saarinen et al., 2018).

Tanhuanpää et al. (2014) developed an ALS application for mapping and monitoring single tree characteristics for the needs of urban forestry. Basically, similar tree detection and characterization methods were used as in Saarinen et al. (2018). The developed application has already been put into practice in the city of Helsinki and the street tree register of the city of Helsinki is based on ALS-based single tree characterization (Figure 3, Tanhuanpää et al., 2014). Although the tree detection accuracies presented in Kaartinen et al. (2012) and Vauhkonen et al. (2012) were not always so appealing, there are forest structures where CHM-based tree detection methods are capable of detecting almost all trees. Peuhkurinen et al. (2007) used CHM-based tree detection with ALS data for preharvest measurements of marked stands. They had two marked Scots pine dominated stands and obtained underestimation of stem number less than 3\% (Figure 16) whereas underestimation of saw log volume was only $0.5 \%$. Already these results prove that most probably there are benefits from single tree information for wood procurement planning. We assume that single tree detection and characterization techniques will be more used in the near future as countrywide open access ALS data will be suitable for single tree detection. Information based on single tree detection can be used side-by-side with information provided by ABA as it will be, for example, easy to obtain single tree information for mature stands that are located within a certain distance from a saw mill. 


\section{Final remarks}

To conclude, methods for individual tree detection and characterization from ALS and photogrammetric point clouds provide information about a large fraction of trees. However, there is still a challenge to make optimal use of the information from the whole point cloud for detecting suppressed and closely growing trees. The most common workflow for tree detection and characterization is to create a CHM (1), smooth the CHM surface (2), and then detect local maximas (3). Tree crowns are then segmented and watershed segmentation is often used (4). Field measurements are required for predicting most of the tree attributes of interest for each crown segment within an area of interest (5). Although single tree techniques often lead to underestimation of trees per hectare, basal area and stem volume, there are already operational applications for single-tree techniques including preharvest measurements and urban planning. As the suitable data sets for single tree detection are coming more widely available, we believe that we are starting to use single tree detection and characterization techniques more and side-by-side with information provided by ABA for many purposes.

\section{References}

Eysn, L., Hollaus, M., Lindberg, E., Berger, F., Monnet, J.-M., Dalponte, M., Kobal, M., Pellegrini, M., Lingua, E., Mongus, D., \& Pfeifer, N. (2015). A Benchmark of Lidar-Based Single Tree Detection Methods Using Heterogeneous Forest Data from the Alpine Space. Forests, Trees and Livelihoods (Vol. 6, Issue 5, 1721-1747).

Hirschmugl, M., Ofner, M., Raggam, J., \& Schardt, M. (2007). Single tree detection in very high resolution remote sensing data. Remote Sensing of Environment (Vol 110, Issue 4, pp. 533-544).

Holopainen, M., Hyyppä, J. \& Vastaranta, M. (2013). Laserkeilaus metsävarojen hallinnassa. Helsingin Yliopiston Metsätieteiden Laitoksen Julkaisuja (Vol 5, pp. 1-75).

Holopainen, M., Vastaranta, M., \& Hyyppä, J. (2014). Outlook for the Next Generation's Precision Forestry in Finland. Forests (Vol. 5, Issue 7, pp. 1682-1694). https://doi.org/10.3390/f5071682

Hyyppä, J., Yu, X., Hyyppä, H., Vastaranta, M., Holopainen, M., Kukko, A., Kaartinen, H., Jaakkola, A., Vaaja, M., Koskinen, J., \& Alho, P. (2012). Advances in Forest Inventory Using Airborne Laser Scanning. Remote Sensing (Vol. 4, Issue 5, pp. 1190-1207).

Hyyppä, J., Yu, X., Kaartinen, H., Kukko, A., Jaakkola, A., Liang, X., Wang, Y., Holopainen, M., Vastaranta, M., \& Hyyppä, H. (2018). Forest Inventory Using Laser Scanning. Topographic Laser Ranging and Scanning (pp. 379-412). https://doi.org/10.1201/9781315154381-12

Kaartinen, H., Hyyppä, J., Yu, X., Vastaranta, M., Hyyppä, H., Kukko, A., Holopainen, M., Heipke, C., Hirschmugl, M., Morsdorf, F., Næsset, E., Pitkänen, J., Popescu, S., Solberg, S., Wolf, B. M., \& Wu, J.-C. (2012). An International Comparison of Individual Tree Detection and Extraction Using Airborne Laser Scanning. Remote Sensing (Vol. 4, Issue 4, pp. 950-974). https://doi.org/10.3390/rs4040950

Koch, B., Heyder, U., \& Weinacker, H. (2006). Detection of Individual Tree Crowns in Airborne Lidar Data. Photogrammetric Engineering \& Remote Sensing (Vol. 72, Issue 4, pp. 357-363). https://doi.org/10.14358/pers.72.4.357

Liang, X., Jaakkola, A., Wang, Y., Hyyppä, J., Honkavaara, E., Liu, J., \& Kaartinen, H. (2014). The Use of a Hand-Held Camera for Individual Tree 3D Mapping in Forest Sample Plots. Remote Sensing (Vol. 6, Issue 7, pp. 6587-6603). 


\section{This is a non-peer reviewed preprint submitted to EarthArXiv}

Magnard, C., Morsdorf, F., Small, D., Stilla, U., Schaepman, M. E., \& Meier, E. (2016). Single tree identification using airborne multibaseline SAR interferometry data. Remote Sensing of Environment (Vol 186, 567-580).

Nevalainen, O., Honkavaara, E., Tuominen, S., Viljanen, N., Hakala, T., Yu, X., ... Tommaselli, A. (2017). Individual Tree Detection and Classification with UAV-Based Photogrammetric Point Clouds and Hyperspectral Imaging. Remote Sensing (Vol. 9, Issue 3, pp. 185). doi:10.3390/rs9030185

Peuhkurinen, J., Maltamo, M., Malinen, J., Pitkänen, J. \& Packalén, P. (2007). Preharvest measurement of marked stands using airborne laser scanning. Forest Science (Vol. 53, Issue 6, pp. 653-661).

Saarinen, N., Vastaranta, M., Näsi, R., Rosnell, T., Hakala, T., Honkavaara, E., Wulder, M., Luoma, V., Tommaselli, A., Imai, N., Ribeiro, E., Guimarães, R., Holopainen, M., \& Hyyppä, J. (2018). Assessing Biodiversity in Boreal Forests with UAV-Based Photogrammetric Point Clouds and Hyperspectral Imaging. Remote Sensing (Vol. 10, Issue 2, p. 338). https://doi.org/10.3390/rs10020338

Siipilehto, J., Lindeman, H., Vastaranta, M., Yu, X., \& Uusitalo, J. (2016). Reliability of the predicted stand structure for clear-cut stands using optional methods: airborne laser scanning-based methods, smartphone-based forest inventory application Trestima and pre-harvest measurement tool EMO. Silva Fennica (Vol. 50, Issue 3). https://doi.org/10.14214/sf.1568

Tanhuanpää, T., Vastaranta, M., Kankare, V., Holopainen, M., Hyyppä, J., Hyyppä, H., Alho, P., \& Raisio, J. (2014). Mapping of urban roadside trees - A case study in the tree register update process in Helsinki City. Urban Forestry \& Urban Greening (Vol. 13, Issue 3, pp. 562-570). https://doi.org/10.1016/j.ufug.2014.03.005

Vastaranta, M., Saarinen, N., Yrttimaa, T., Kankare, V., \& Junttila, S. (2020). Monitoring Forests in Space and Time Using Close-Range Sensing. https://doi.org/10.20944/preprints202002.0300.v1

Vastaranta, M., Wulder, M. A., White, J. C., Pekkarinen, A., Tuominen, S., Ginzler, C., Kankare, V., Holopainen, M., Hyyppä, J., \& Hyyppä, H. (2013). Airborne laser scanning and digital stereo imagery measures of forest structure: comparative results and implications to forest mapping and inventory update. Canadian Journal of Remote Sensing (Vol. 39, Issue 5, pp. 382-395). https://doi.org/10.5589/m13-046

Vastaranta, M., Yrttimaa, T., Saarinen, N., Yu, X., Karjalainen, M., Nurminen, K., Karila, K., Kankare, V., Luoma, V., Pyörälä, J., Junttila, S., Tanhuanpää, T., Kaartinen, H., Kukko, A., Honkavaara, E., Jaakkola, A., Liang, X., Wang, Y., Vaaja, M., Hyyppä, H., Katoh, M., Wulder, M.A., Holopainen, M., Hyyppä, J. (2018). Airborne laser scanning outperforms the alternative 3D techniques in capturing variation in tree height and forest density in southern boreal forests. Baltic Forestry (Vol. 28, Issue 2, pp. 268-277).

Vastaranta, M., Yu, X., Luoma, V., Karjalainen, M., Saarinen, N., Wulder, M. A., White, J. C., Persson, H. J., Hollaus, M., Yrttimaa, T., Holopainen, M., \& Hyyppä, J. (2018). Aboveground forest biomass derived using multiple dates of WorldView-2 stereo-imagery: quantifying the improvement in estimation accuracy. International Journal of Remote Sensing (Vol. 39, Issue 23, pp. 8766-8783). https://doi.org/10.1080/01431161.2018.1492176

Vauhkonen, J., Ene, L., Gupta, S., Heinzel, J., Holmgren, J., Pitkanen, J., Solberg, S., Wang, Y., Weinacker, H., Hauglin, K. M., Lien, V., Packalen, P., Gobakken, T., Koch, B., Naesset, E., Tokola, T., \& Maltamo, M. (2012). Comparative testing of single-tree detection algorithms under different types of forest. Forestry (Vol. 85, Issue 1, pp. 27-40). https://doi.org/10.1093/forestry/cpr051

Vauhkonen, J., Korpela, I., Maltamo, M., \& Tokola, T. (2010). Imputation of single-tree attributes using airborne laser scanning-based height, intensity, and alpha shape metrics. Remote Sensing of Environment (Vol. 114, Issue 6, pp. 1263-1276). https://doi.org/10.1016/j.rse.2010.01.016

Wang, Y., Weinacker, H., \& Koch, B. (2008). A Lidar Point Cloud Based Procedure for Vertical Canopy Structure Analysis And 3D Single Tree Modelling in Forest. Sensors (Vol. 8, Issue 6, pp. 
3938-3951). https://doi.org/10.3390/s8063938

White, J. C., Wulder, M. A., Varhola, A., Vastaranta, M., Coops, N. C., Cook, B. D., Pitt, D., \& Woods, M. (2013). A best practices guide for generating forest inventory attributes from airborne laser scanning data using an area-based approach. The Forestry Chronicle (Vol. 89, Issue 06, pp. 722-723). https://doi.org/10.5558/tfc2013-132

White, J., Wulder, M., Vastaranta, M., Coops, N., Pitt, D., \& Woods, M. (2013). The Utility of Image-Based Point Clouds for Forest Inventory: A Comparison with Airborne Laser Scanning. Forests (Vol. 4, Issue 3, pp. 518-536). https://doi.org/10.3390/f4030518

Yu, X., Hyyppä, J., Vastaranta, M., Holopainen, M., \& Viitala, R. (2011). Predicting individual tree attributes from airborne laser point clouds based on the random forests technique. ISPRS Journal of Photogrammetry and Remote Sensing (Vol. 66, Issue 1, pp. 28-37). https://doi.org/10.1016/j.isprsjprs.2010.08.003

Zawawi, A. A., Shiba, M., \& Jemali, N. J. N. (2015). Accuracy of LiDAR-based tree height estimation and crown recognition in a subtropical evergreen broad-leaved forest in Okinawa, Japan. In Forest Systems (Vol. 24, Issue 1, p. 002). https://doi.org/10.5424/fs/2015241-05476

Zhen, Zhen, Z., Quackenbush, L., \& Zhang, L. (2016). Trends in Automatic Individual Tree Crown Detection and Delineation-Evolution of LiDAR Data. Remote Sensing (Vol. 8, Issue 4, p. 333). 